\title{
Wet Oxidation Behavior of Near-Stoichiometric SiC Fibres in the Simulated Aeroengine Circumstance
}

\author{
Liang Li $\left(\mathbb{D},{ }^{1,2} \mathrm{Ke}\right.$ Jian, ${ }^{2}$ Xianhe Mao, ${ }^{1}$ and Yifei Wang ${ }^{2}$ \\ ${ }^{1}$ Northwest Institute of Nuclear Technology, Xian 710024, China \\ ${ }^{2}$ Science and Technology on Advanced Ceramic Fibers \& Composites Laboratory, \\ National University of Defense Technology, Changsha 410073, China
}

Correspondence should be addressed to Liang Li; 546780152@qq.com

Received 7 January 2018; Revised 20 May 2018; Accepted 12 June 2018; Published 1 August 2018

Academic Editor: Michael I. Ojovan

Copyright (C) 2018 Liang Li et al. This is an open access article distributed under the Creative Commons Attribution License, which permits unrestricted use, distribution, and reproduction in any medium, provided the original work is properly cited.

\begin{abstract}
The precursor-derived and near-stoichiometric $\mathrm{SiC}$ fibres (KD-S) were exposed at $1000-1500^{\circ} \mathrm{C}$ for $1 \mathrm{~h}$ in the simulated aeroengine circumstance of $\mathrm{P}_{\mathrm{H}_{2} \mathrm{O}: \mathrm{O}_{2}: \mathrm{Ar}}=14: 8: 78 \mathrm{KPa}$ with the gas rate of $200 \mathrm{ml} / \mathrm{min}$. The results indicated that the oxidized KD-S fibres were covered by silica layer. The oxygen content, grain size of silica, and oxide layer thickness increased, whereas the tensile strength decreased with rising annealing temperature. $\mathrm{KD}-\mathrm{S}$ fibres treated under simulated aeroengine circumstances showed larger $\mathrm{SiO}_{2}$ grain size, thicker silica layer, and better residual strength than those annealed in dry air. The steam could accelerate the oxidation on KD-S fibres by reducing the active energy. The influence of water vapour on the oxidation behavior of KD-S SiC fibres was investigated and discussed as well.
\end{abstract}

\section{Introduction}

Silicon carbide fibres $\left(\mathrm{SiC}_{\mathrm{f}}\right)$ with high tensile strength, high elastic modulus, and excellent thermal stability have been applied as the reinforcement materials for ceramic-matrix composites (CMCs). The continuous silicon carbide reinforced ceramic-matrix composites $\left(\mathrm{SiC}_{\mathrm{f}}\right.$-CMCs) have been widely used in military equipment and aircraft components such as combustor liners and turbine vanes $[1,2]$. Although a protective silica layer could be generated during passive oxidation, the oxidation resistance of $\mathrm{SiC}$ fibres still needs to be improved. In combustion process, the water vapour produced from burning hydrocarbon in air is calculated to be $5-10 \%$ in the combustion gas under equilibrium conditions [3]. Therefore, the reaction of $\mathrm{SiC}$ fibres with water vapour is a concern.

Previous studies [4-6] on microstructure evolutions of $\mathrm{SiC}$ materials in various oxidizing environments have demonstrated that the water vapour increases the oxidation rate of $\mathrm{SiC}$ in the passive regime and affects the oxidation mechanism markedly. And these works [7-9] also show that the fibres oxidation follows a linear-parabolic law due to the silica film protecting inner fibre to be further oxidized, and the formation and structural evolution of the film are greatly affected by the heat treatment temperature or time and/or oxidizing environment. Additionally, some researches $[10,11]$ were conducted under the simulated aeroengine circumstance to guide the design of the $\mathrm{SiC}$ fibres microstructure for a better service in the future.

Many works, mainly focused on Hi-Nicalon fibres (manufactured by Carbon Company, Japan), on the oxidation behavior of SiC fibres have been documented. However, wet oxidation behavior of KD-S (a type of precursor-derived and near-stoichiometric SiC fibres, manufactured by National University Defense Technology, China), annealed under simulated aeroengine circumstance, has seldom been reported. Therefore, in this paper, an environment of $\mathrm{P}_{\mathrm{H}_{2} \mathrm{O}: \mathrm{O}_{2}: \mathrm{Ar}}=$ $14: 8: 78 \mathrm{KPa}$ was used to simulate the aeroengine circumstance. The $\mathrm{KD}-\mathrm{S} \mathrm{SiC}$ fibres were exposed in the simulated atmosphere at $1000-1500^{\circ} \mathrm{C}$ for $1 \mathrm{~h}$ to evaluate the fibres hightemperature properties and to explore the fibres wet oxidation behaviors. 
TABLE 1: The typical properties of KD-S fibres after desizing.

\begin{tabular}{lcccccccc}
\hline Fibres & $\begin{array}{c}\text { Diameter } \\
(\mu \mathrm{m})\end{array}$ & $\begin{array}{c}\text { Tensile strength } \\
(\mathrm{GPa})\end{array}$ & $\begin{array}{c}\text { Modulus } \\
(\mathrm{GPa})\end{array}$ & $\begin{array}{c}\text { Density } \\
\left(\mathrm{g} / \mathrm{cm}^{3}\right)\end{array}$ & $\begin{array}{c}\text { Elongation } \\
(\%)\end{array}$ & $\begin{array}{c}\text { Oxygen } \\
(\text { wt.\%) }\end{array}$ & $\begin{array}{c}\text { Carbon } \\
(\text { wt.\%) }\end{array}$ & $\begin{array}{c}\text { C/Si } \\
(\text { atomic })\end{array}$ \\
\hline KD-S & 11 & 2.8 & 320 & 2.87 & 1.23 & 1.0 & 31.8 & 1.05 \\
\hline
\end{tabular}

\section{Experimental Procedures}

The KD-S SiC fibres used in this study were produced by our laboratory using the procedure of Yajima $[2,5]$. These nearstoichiometric $\mathrm{SiC}$ fibres were obtained by adding hydrogen to eliminate excess carbon during sintering process. The KDS fibres were firstly desized by pyrolysis at $500^{\circ} \mathrm{C}$ in air for 20 minutes to remove polyvinyl alcohol. Table 1 shows some typical properties of KD-S fibres after desizing.

Under the protective atmosphere of argon, the desized fibres were put into high-temperature furnace and heated to $1000,1100,1200,1300,1400$, and $1500^{\circ} \mathrm{C}$, respectively, with the heating rate of $10^{\circ} \mathrm{C} / \mathrm{min}$. On reaching the designed temperatures, the atmosphere of $\mathrm{P}_{\mathrm{H}_{2} \mathrm{O}: \mathrm{O}_{2}: \mathrm{Ar}}=14: 8: 78 \mathrm{KPa}$ was introduced into the furnace with a flow rate of $200 \mathrm{ml} / \mathrm{min}$ to simulate the operating circumstance of aeroengines. After a holding duration of 1 hour, fibres were cooled down with the protection of argon flow. The same KD-S fibres were also annealed in dry air at $1000-1500^{\circ} \mathrm{C}$ for $1 \mathrm{~h}$ for comparison.

Tensile tests were carried out at room temperature on monofilaments before and after the annealing treatment, using a monofilament tensile testing machine (Testometric Micro 350, UK), with $25 \mathrm{~mm}$ for the test length and 5 $\mathrm{mm} / \mathrm{min}$ for the tensile speed, and each result is the average of 24 times tests. Oxygen content was measured by oxygen elemental analyser (EMGA-320V2, Horiba, Japan). The phases existing in fibres were identified by X-ray diffractometer (XRD, D8 Advance, Bruker AXS, Germany), with $40 \mathrm{kV}$ voltage, $30 \mathrm{~mA}$ current, $\mathrm{Cu} \mathrm{K} \alpha$ diffraction patterns, and scanning speed of $0.1^{\circ} / \mathrm{s}$. By scanning electron microscope (SEM, Quanta FEG 250, FEI, USA), secondary electron images were obtained to observe the morphology of fibres, whereas the thicknesses of oxide layers were measured by the contrast in backscattered electron images [10].

\section{Experimental Results}

3.1. Tensile Test of KD-S Fibres. Figure 1 shows residual tensile strength of KD-S SiC fibres before and after annealing under simulated atmosphere of $\mathrm{P}_{\mathrm{H}_{2} \mathrm{O}: \mathrm{O}_{2}: \mathrm{Ar}}=14: 8: 78 \mathrm{KPa}$ and dry air at $1000,1100,1200,1300,1400$, and $1500^{\circ} \mathrm{C}$ for $1 \mathrm{~h}$, respectively. Obviously, the growth of annealing temperature caused increasingly severe strength degradation. The fibres exhibit higher strength after heat treatment under simulated atmosphere than in dry air. As typical brittle ceramic materials, the mechanical properties of $\mathrm{SiC}$ fibres show wide dispersion. Therefore, the measured strengths of KD-S perform scatting ranges in Figure 1.

3.2. Oxygen Content and Silica Layer Thickness. The oxygen contents of KD-S SiC fibres after annealing under simulated atmosphere and in dry air, respectively, were presented in Figure 2(a). It clearly appeared that the oxygen content increased with rising annealing temperature, and the oxygen contents of fibres annealed under simulated atmosphere were higher than those in fibres annealed in dry air. The original oxygen content of KD-S fibres was 1.0 wt.\%, which markedly increased to $13 \mathrm{wt} . \%$ after the annealing at $1500^{\circ} \mathrm{C}$ for $1 \mathrm{~h}$ in simulated atmosphere.

Figure 2(b) shows the effect of temperature and atmosphere on the silicon oxide layer thickness of KD-S SiC fibres after annealing treatment for $1 \mathrm{~h}$ in simulated atmosphere and dry air. Apparently from Figure 2(b), the oxide layer thickness grew with the increase of annealing temperature. Also, it is obvious that the silica layer on fibres exposed under simulated atmosphere was thicker than that on fibres annealed in dry air.

3.3. X-Ray Diffraction Profile. The XRD patterns of SiC fibres before and after annealing under simulated atmosphere were displayed in Figure 3(a). Three main peaks were assigned to the (111) plane, (220) plane, and (311) plane of $\beta$-SiC existing in the patterns of $\mathrm{KD}-\mathrm{S} \mathrm{SiC}$ fibres. These three main peaks remained unchanged with rising annealing temperature, indicating the presence of $\beta$-SiC in all the fibres before and after annealing treatments. The diffraction peak of $\alpha$-cristobalite appeared at $2 \theta=21.98^{\circ}$ after the annealing treatment at $1300^{\circ} \mathrm{C}$ for $1 \mathrm{~h}$ under simulated atmosphere and then gradually sharpened as the temperature increased to 1400 and $1500^{\circ} \mathrm{C}$, which indicated the formation and crystallization of $\alpha$-cristobalite by oxidation.

It can be observed from Figure 3(b) that peaks of $\beta$-SiC show little difference in fibres annealed both under simulated atmosphere and in dry air. But the grain sizes of $\alpha$-cristobalite grew larger in fibres annealed under simulated atmosphere than those in dry air. These results indicate that annealing temperature and steam have little effect on the growth of $\beta$ $\mathrm{SiC}$ grains, while they obviously accelerate the crystallization of $\alpha$-cristobalite.

3.4. Morphology. To further analyse the oxidation degradation of KD-S SiC fibres after annealing treatment under simulated aeroengine atmosphere, the surfaces and cross sections of $\mathrm{KD}-\mathrm{S} \mathrm{SiC} \mathrm{fibres} \mathrm{before} \mathrm{and} \mathrm{after} \mathrm{annealing} \mathrm{were} \mathrm{observed}$ via SEM. Figure 4(a-1,a-2) shows the morphologies of KD-S fibres after annealing in simulated atmosphere at $1100^{\circ} \mathrm{C}$ for $1 h$; it can be seen that the fibres surfaces were very smooth and the edge of cross section was even. The fibres were coated by a thin oxide film. With temperature rising to $1300^{\circ} \mathrm{C}$, as shown in Figure 4(b-1 and b-2), the fibres surfaces became rough and the cross sections were relatively uneven. After annealing treatment at $1500^{\circ} \mathrm{C}$, as can be seen obviously from Figure $4(c-1, c-2)$, there were cracks and pits on the fibres 


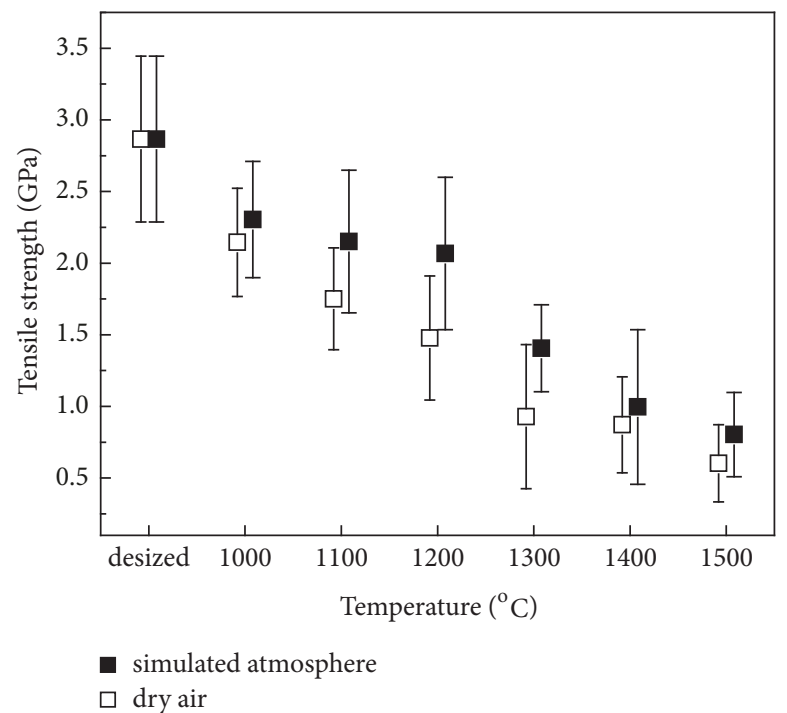

Figure 1: The tensile strength of $\mathrm{KD}-\mathrm{S}$ fibres after annealing at $1000-1500^{\circ} \mathrm{C}$ for $1 \mathrm{~h}$.

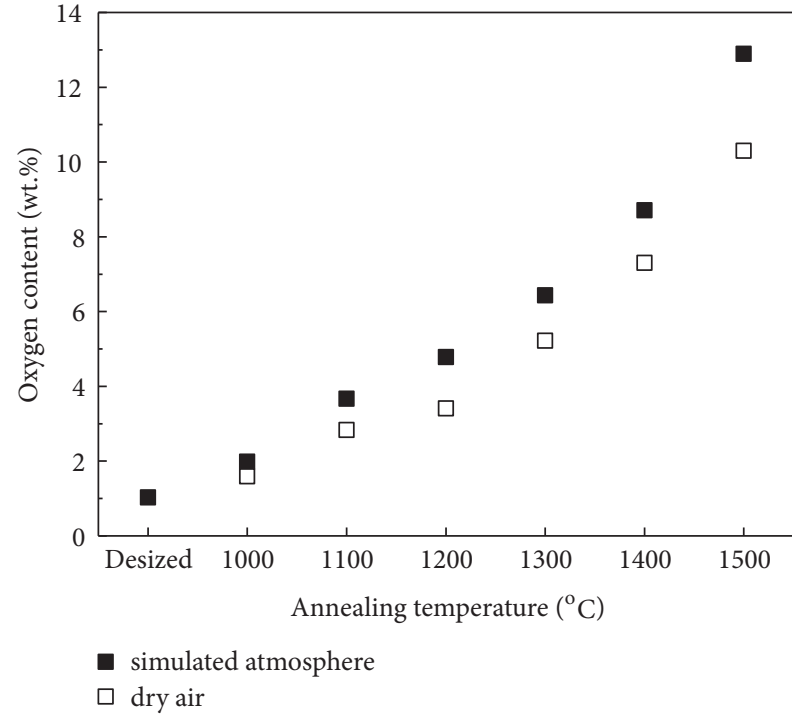

(a)

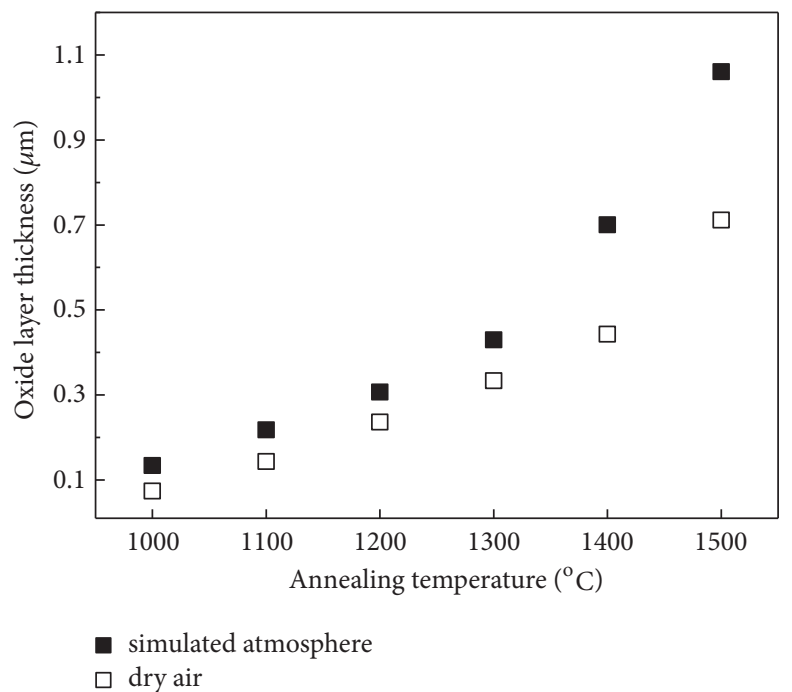

(b)

Figure 2: The oxygen content and oxide layer thickness of KD-S fibres after annealing at $1000-1500^{\circ} \mathrm{C}$ for 1 h. (a) Oxygen content and (b) oxide layer thickness.

surfaces, while the fibre core was covered by a thick silica layer.

\section{Discussion}

4.1. Effects of Steam on the Oxidation Kinetics. Silicon carbide materials could be oxidized in the passive/active oxidation regime, which is influenced by the purity and microstructure of materials, as well as the temperature and oxygen partial pressure [2]. Previous studies have confirmed that $\mathrm{SiC}$ fibres with low oxygen content would be passively oxidized in both wet air and dry air [12]. And the reactions are shown as follows:

$$
\begin{aligned}
& \mathrm{SiC}(s)+3 \mathrm{H}_{2} \mathrm{O}(g) \longrightarrow \mathrm{SiO}_{2}(s)+3 \mathrm{H}_{2}(g)+\mathrm{CO}(g) \\
& \mathrm{SiC}(s)+\frac{3}{2 \mathrm{O}_{2}(g)} \longrightarrow \mathrm{SiO}_{2}(s)+\mathrm{CO}(g)
\end{aligned}
$$

Generally, oxide film would form during the passive oxidation. The resistance for the oxidizing medium diffusion through oxide film would increase with thicker silica layer. Consequently, the silica layer could protect the inner $\mathrm{SiC}$ fibres from further oxidation. In the model of cylindrical fibres, follow the two-dimensional disconstrained rate equation for diffusion control [13]:

$$
(1-X) * \ln (1-X)+X=K_{d} * t
$$




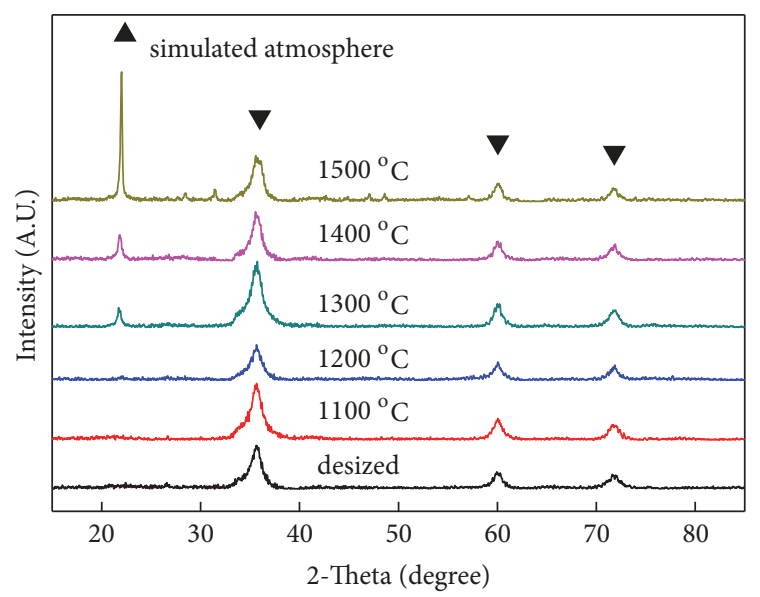

$\Delta \alpha$-Cristobalite

$\nabla \beta-\mathrm{SiC}$

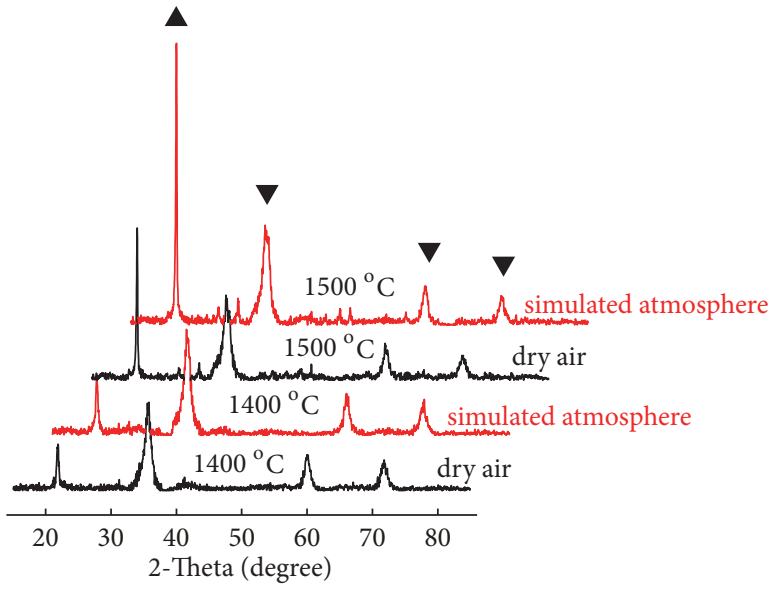

$\Delta \alpha$-Cristobalite

$\nabla \beta$-SiC

(a)

(b)

FIGURE 3: The XRD patterns of KD-S fibres after annealing for $1 \mathrm{~h}$. (a) Under simulated atmosphere. (b) Under simulated atmosphere and under dry air.
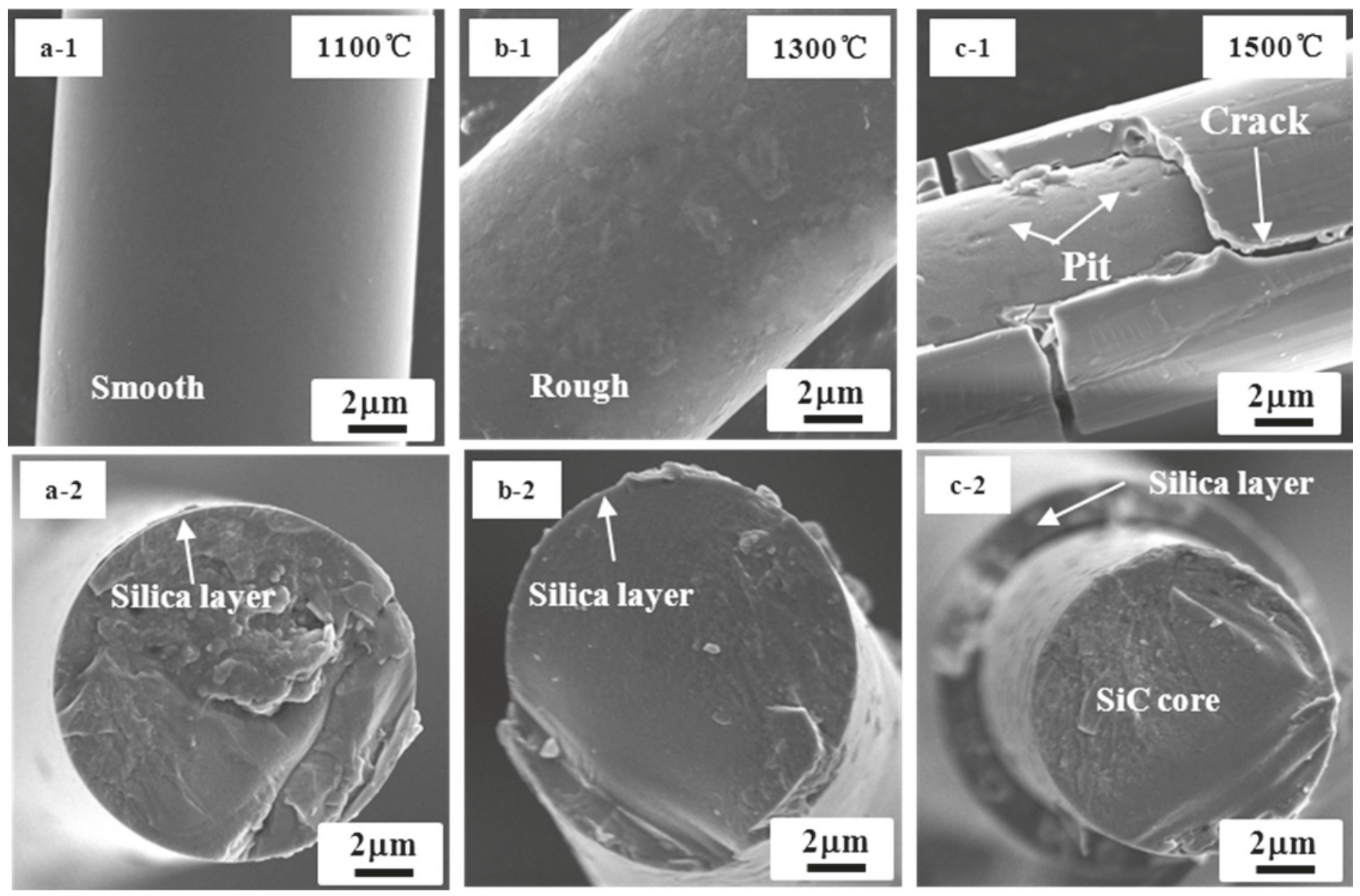

FigurE 4: SEM graphs of KD-S fibres after annealing under simulated atmospheres for $1 \mathrm{~h}$. (a) At $1100^{\circ} \mathrm{C}$, (b) at $1300^{\circ} \mathrm{C}$, and (c) at $1500^{\circ} \mathrm{C}$. 


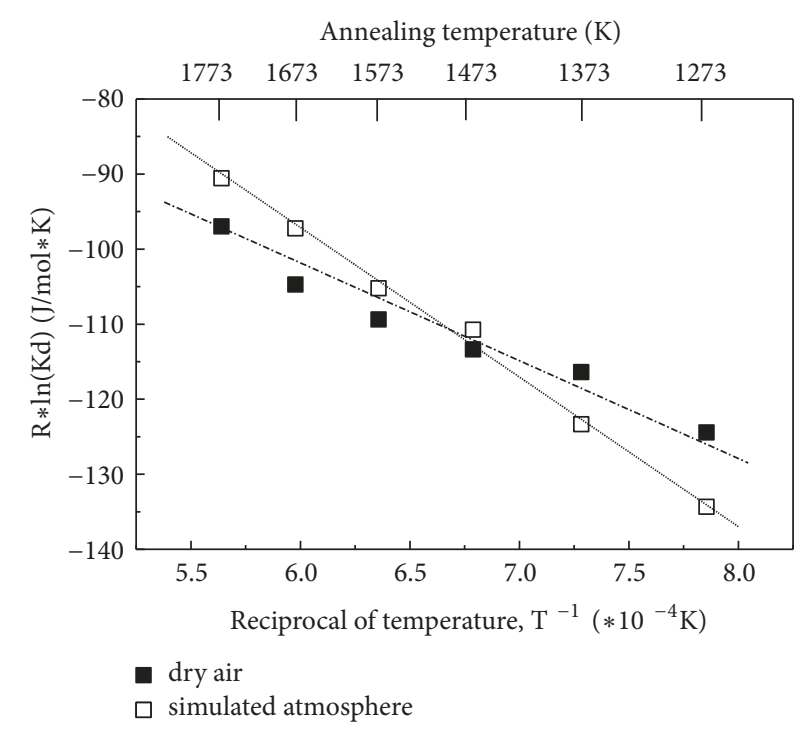

FIGURE 5: Arrhenius equation plot of oxide rate for KD-S fibres in simulated atmosphere and dry air.
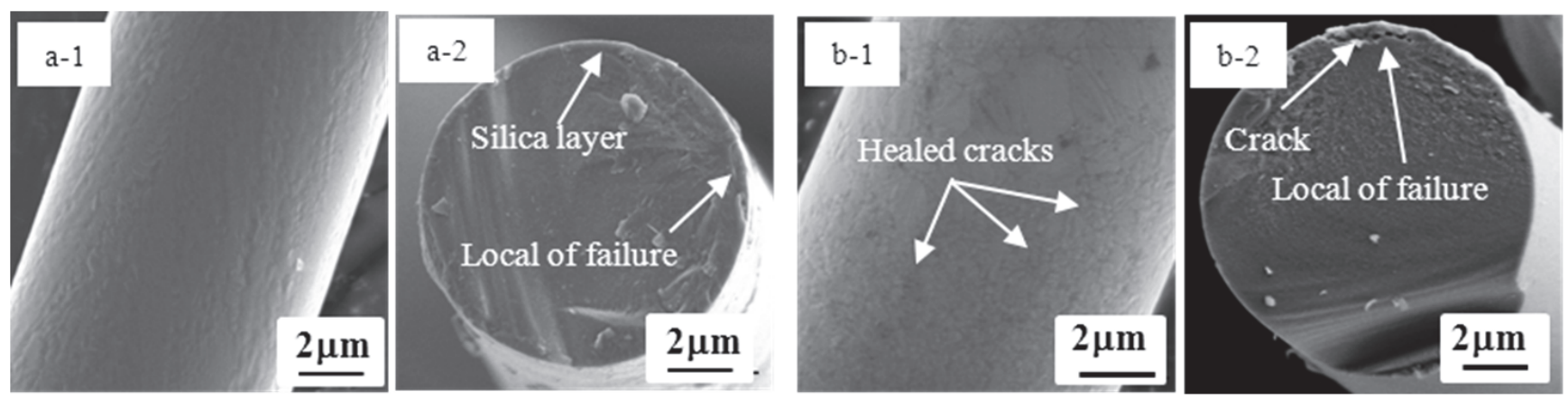

FIGURE 6: The morphologies of KD-S after annealing at $1400^{\circ} \mathrm{C}$ for $1 \mathrm{~h}$. (a) Under simulated atmosphere. (b) Under dry air.

where $X$ stands for the oxidized fraction, $K_{d}$ represents the rate constant for diffusion control step, and $t$ is the oxidation time.

Although the density of silicon carbide differs from that of the silica layer, experimental results have shown that the average change in diameters of KD-S fibres is less than $1.5 \%$ after oxidation. Therefore, the diameter of KD-S fibre is regarded as a constant during the oxidation, with negligibly small change in diameter. Thus, $X$, the oxidation fraction, could be expressed as follows:

$$
X=1-\frac{\left(r_{0}-m\right)^{2}}{r_{0}^{2}}
$$

where $r_{0}$ is the initial fibres radius and $m$ is the thickness of silica layer.

The Arrhenius equation to calculate reaction active energy is as follows:

$$
K=A * e^{-E /(R T)}
$$

where $K$ stands for the rate constant; $A$ is a system constant; $E$ represents the active energy $(\mathrm{KJ} / \mathrm{mol}) ; R$ means universal gas constant $\left(8.314 \mathrm{~J} * \mathrm{~mol}^{-1} * \mathrm{~K}^{-1}\right)$; $T$ is thermodynamic temperature $(\mathrm{K})$.

We could deform (5) into (6), in which $R * \ln K$ is linear to $T^{-1}$ with curve slope standing for the active energy.

$$
R * \ln K=-E * T^{-1}+R * \ln A
$$

The rate constant was calculated by substituting (4) into (3) and using the oxide layer thickness dates shown in Figure 2(b). Then substitute rate constant at different temperature into (6) and the results are presented in Figure 5. It can be calculated from curve slope that the reaction active energies under simulated atmosphere and in dry air are $Q_{\text {wet }}$ $=135 \mathrm{KJ} / \mathrm{mol}$ and $Q_{d r y}=200 \mathrm{KJ} / \mathrm{mol}$, respectively. This result indicates that the water vapour may accelerate $\mathrm{KD}-\mathrm{S} \mathrm{SiC}$ fibres oxidizing by reducing the oxidation active energy.

4.2. Effects of Steam on Mechanical Properties. Figure 6 shows the morphologies of $\mathrm{KD}$-S fibres after annealing at $1400^{\circ} \mathrm{C}$ for $1 \mathrm{~h}$. As displayed in Figure 6(a-1,a-2), when annealed in simulated atmosphere, the fibres surface has formed compact 
oxide film and the cross section is relatively flat. The failure of rupture located in the interface between inner fibre and silica layer. However, when the fibres were annealed in dry air as shown in Figure 6(b-1,b-2), there were many healed microcracks in the silica layer and crack in the cross section, which was caused by the mismatch of thermal expansion coefficients between inner fibre and outer silica layer. Obviously from the comparison of morphologies, the strength degradation of fibres annealed in dry air was more severe than that of fibres annealed under simulated atmosphere, which is consistent with the results in Figure 1.

At the same time, the XRD results indicate that the amorphous silica preferably crystallized into $\alpha$-cristobalite when KD-S fibres were annealed in simulated atmosphere than in dry air. The $\alpha$-cristobalite crystals embedded within amorphous silica could generate the fine grain strengthening, which may be beneficial to the retention of tensile strength $[10,14]$. All above issues may be the reasons to contribute to the result that the residue strength of $\mathrm{KD}-\mathrm{S} \mathrm{SiC}$ fibres annealed under simulated atmosphere was higher than that in dry air.

\section{Conclusion}

Wet oxidation behaviors of a precursor-derived and nearstoichiometric SiC fibres (KD-S) were investigated in a simulated aeroengine circumstance of $\mathrm{P}_{\mathrm{H}_{2} \mathrm{O}: \mathrm{O}_{2}: \mathrm{Ar}}=14: 8: 78 \mathrm{kPa}$ at $1000-1500^{\circ} \mathrm{C}$ for $1 \mathrm{~h}$ with gas rate of $200 \mathrm{ml} / \mathrm{min}$. And the mechanical and structural evolutions of KD-S were characterized. The following conclusions were drawn from the experimental results.

(1) The residual tensile strength decreased with rising annealing temperature both in simulated atmosphere and in dry air, but retention of strength in simulated atmosphere is always higher than that in dry air.

(2) The oxidizing temperature and water vapour have little effect on the growth of $\beta$-SiC grains, while they obviously promote the crystallization of $\alpha$-cristobalite.

(3) The water vapour accelerates the oxidation rates and reduces the active energy. The oxidation active energies of KD-S SiC fibres in simulated atmosphere and in dry air are $Q_{\text {wet }}=135 \mathrm{KJ} / \mathrm{mol}$ and $Q_{d r y}=200 \mathrm{KJ} / \mathrm{mol}$, respectively.

\section{Data Availability}

The data used to support the findings of this study are available from the corresponding author upon request.

\section{Disclosure}

The abstract of this article has been included in the abstract book of the IUMRS-ICA 2016 conference [15].

\section{Conflicts of Interest}

There are no conflicts of interest related to this paper.

\section{Acknowledgments}

This work is supported by the National Natural Science Foundation of China (51172280). The authors greatly appreciate the thoughtful comments and valuable suggestions given by Dr. Qiance Zhang from the University of Manchester.

\section{References}

[1] H. Ohnabe, S. Masaki, M. Onozuka, K. Miyahara, and T. Sasa, "Potential application of ceramic matrix composites to aeroengine components," Composites Part A: Applied Science and Manufacturing, vol. 30, no. 4, pp. 489-496, 1999.

[2] K. Okamura, T. Shimoo, K. Suzuya, and K. Suzuki, "SiC-based ceramic fibers prepared via organic-to-inorganic conversion process-a review," Journal of the Ceramic Society of Japan, vol. 114, no. 1330, pp. 445-454, 2006.

[3] N. S. Jacobson, "Corrosion of Silicon-Based Ceramics in Combustion Environments," Journal of the American Ceramic Society, vol. 76, no. 1, pp. 3-28, 1993.

[4] Y. Chai, X. Zhou, and H. Zhang, "Effect of oxidation treatment on KD-II SiC fiber-reinforced SiC composites," Ceramics International, vol. 43, no. 13, pp. 9934-9940, 2017.

[5] A. R. Bunsell and A. Piant, "A review of the development of three generations of small diameter silicon carbide fibres," Journal of Materials Science, vol. 41, no. 3, pp. 823-839, 2006.

[6] S. Cao, J. Wang, and H. Wang, "Effect of heat treatment on the microstructure and tensile strength of KD-II SiC fibers," Materials Science and Engineering: A Structural Materials: Properties, Microstructure and Processing, vol. 673, pp. 55-62, 2016.

[7] R. S. Hay and R. J. Chater, "Oxidation kinetics strength of HiNicalonTM-S SiC fiber after oxidation in dry and wet air," Journal of the American Ceramic Society, vol. 100, no. 9, pp. 41104130, 2017.

[8] J. J. Sha, T. Hinoki, and A. Kohyama, “Thermal and mechanical stabilities of Hi-Nicalon $\mathrm{SiC}$ fiber under annealing and creep in various oxygen partial pressures," Corrosion Science, vol. 50, no. 11, pp. 3132-3138, 2008.

[9] T.-E. Kim, K.-E. Khishigbayar, and K. Y. Cho, "Effect of heating rate on the properties of silicon carbide fiber with chemicalvapor-cured polycarbosilane fiber," Journal of Advanced Ceramics, vol. 6, no. 1, pp. 59-66, 2017.

[10] R. Yao, Z. Feng, L. Chen, Y. Zhang, and B. Zhang, "Oxidation behavior of Hi-Nicalon $\mathrm{SiC}$ monofilament fibres in air and $\mathrm{O}_{2}$ $\mathrm{H}_{2} \mathrm{O}$-Ar atmospheres," Corrosion Science, vol. 57, pp. 182-191, 2012.

[11] S. Li, Z. Feng, H. Mei, and L. Zhang, "Mechanical and microstructural evolution of Hi-Nicalon Trade Mark SiC fibers annealed in $\mathrm{O}_{2}-\mathrm{H}_{2} \mathrm{O}$-Ar atmospheres," Materials Science and Engineering: A Structural Materials: Properties, Microstructure and Processing, vol. 487, no. 1-2, pp. 424-430, 2008.

[12] J. J. Sha, T. Hinoki, and A. Kohyama, "Microstructure and Mechanical Properties of Hi-Niclaon ${ }^{T M}$ Type S Fibers Annealed and Crept in Various Oxygen Partial Pressures," Materials Characterization, vol. 60, pp. 796-802, 2009.

[13] T. Shimoo, F. Toyoda, and K. Okamura, "Oxidation kinetics of low-oxygen silicon carbide fiber," Journal of Materials Science, vol. 35, no. 13, pp. 3301-3306, 2000.

[14] R. S. Hay, "Growth stress in $\mathrm{SiO}_{2}$ During Oxidation of $\mathrm{SiC}$ Fibers," Journal of Applied Physics, vol. 111, no. 6, Article ID 063527, 2012.

[15] L. Li, K. Jian, and Y. F. Wang, "Wet Oxidation Behavior of NearStoichiometric SiC fibers (KD-S) in Simulated Aeroengine Circumstance," in Proceedings of the The abstract book of the IUMRS-ICA 2016 conference, T. Advanced Fiber and Nanocomposites, pp. 42-43, 2016. 


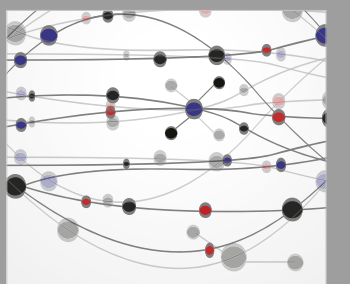

The Scientific World Journal
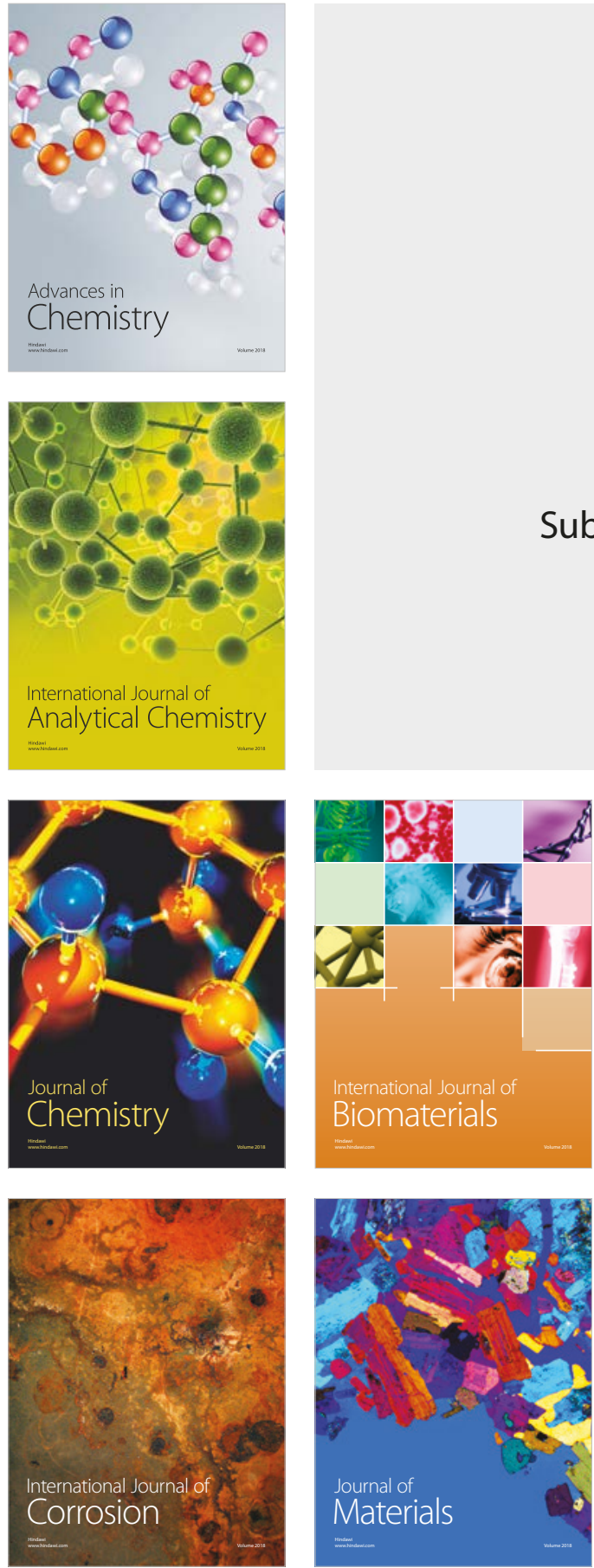

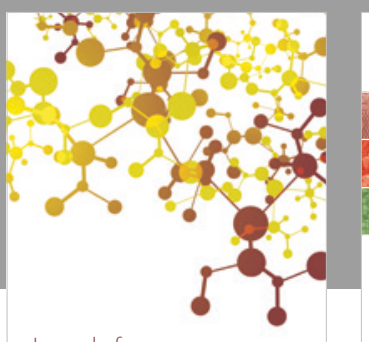

Journal of

Applied Chemistry
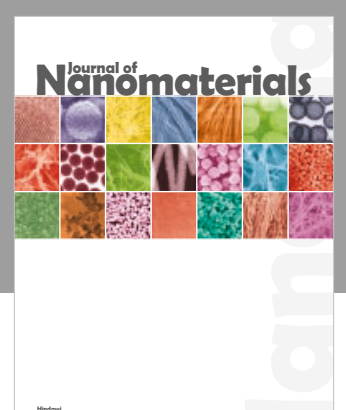

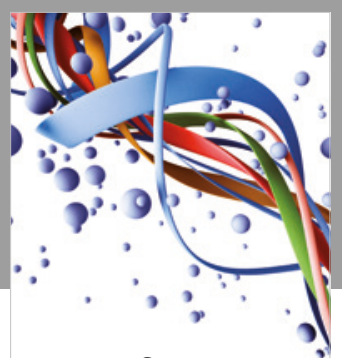

Scientifica

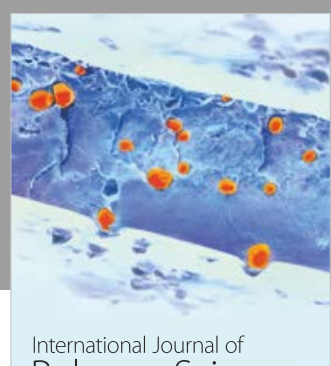

Polymer Science

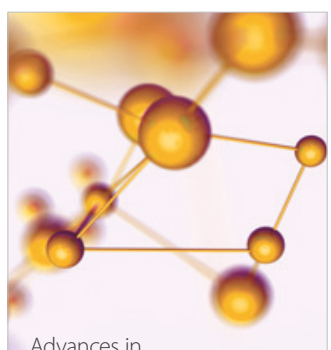

Physical Chemistry
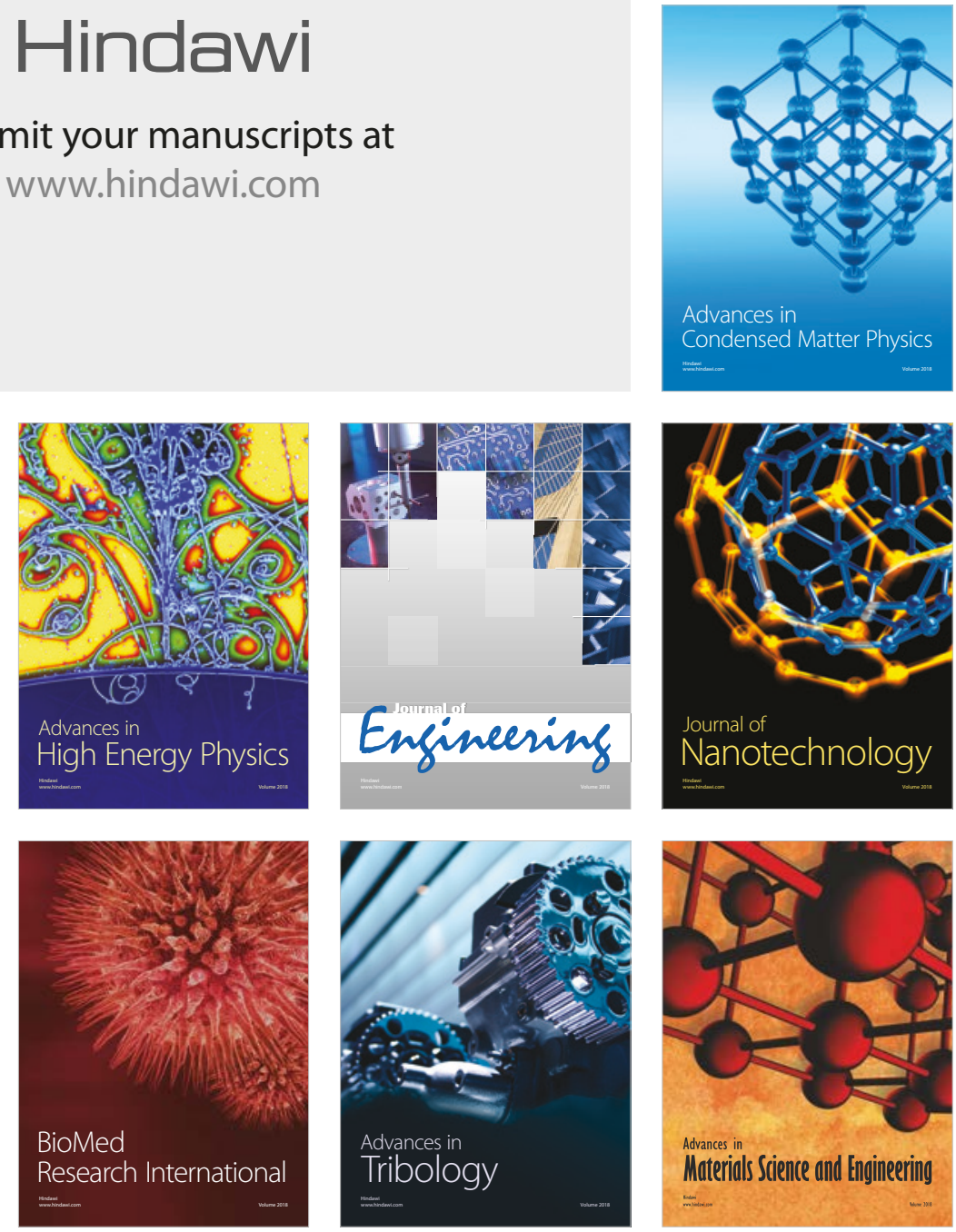